\title{
Characterization of a Novel Breast Carcinoma Xenograft and Cell Line Derived from a BRCA1 Germ-Line Mutation Carrier
}

\author{
Oskar T. Johannsson, Synnöve Staff, Johan Vallon-Christersson, Soili Kytöla, \\ Thorarinn Gudjonsson, Karin Rennstam, Ingrid A. Hedenfalk, Adewale Adeyinka, \\ Elisabeth Kjellén, Johan Wennerberg, Bo Baldetorp, Ole W. Petersen, \\ Håkan Olsson, Stina Oredsson, Jorma Isola, and Åke Borg
}

\begin{abstract}
Departments of Oncology (OTJ, JV-C, IAH, KR, EK, BB, HO, Jl, ÅB), Otorhinolaryngology/Head and Neck Surgery (JW), and Clinical Genetics (AA), University Hospital, Lund, and Department of Cell and Organism Biology (SO), Lund University, Lund, Sweden; Laboratory of Cancer Biology, Institute of Medical Technology, Tampere University and University Hospital, Tampere, Finland (JI, SS); Department of Molecular Medicine, Karolinska Hospital, Stockholm, Sweden (SK); and Department of Medical Anatomy, The Panum Institute, University of Copenhagen, Copenhagen, Denmark (TG, OWP)
\end{abstract}

\begin{abstract}
SUMMARY: A human tumor xenograft ( $\mathrm{L} 56 \mathrm{Br}-\mathrm{X} 1)$ was established from a breast cancer axillary lymph node metastasis of a 53-year-old woman with a BRCA1 germ-line nonsense mutation (1806C > T; Q563X), and a cell line (L56Br-C1) was subsequently derived from the xenograft. The xenograft carries only the mutant BRCA1 allele and expresses mutant BRCA1 mRNA but no BRCA1 protein as determined by immunoprecipitation or Western blotting. The primary tumor, lymph node metastasis, and xenograft were hypodiploid by DNA flow cytometry, whereas the cell line displayed an aneuploidy apparently developed via polyploidization. Cytogenetic analysis, spectral karyotyping, and comparative genomic hybridization of the cell line revealed a highly complex karyotype with numerous unbalanced translocations. The xenograft and cell line had retained a somatic TP53 missense mutation (S215I) originating from the primary tumors, as well as a lack of immunohistochemically detectable expression of steroid hormone receptors, epidermal growth factor receptor, human epidermal growth factor receptor 2 (HER-2), and keratin 8. Global gene expression analysis by cDNA microarrays supported a correlation between the expression profiles of the primary tumor, lymph node metastasis, xenograft, and cell line. We conclude that $\mathrm{L} 56 \mathrm{Br}-\mathrm{X} 1$ and $\mathrm{L} 56 \mathrm{Br}-\mathrm{C} 1$ are useful model systems for studies of the pathogenesis and new therapeutic modalities of BRCA1-induced human breast cancer. (Lab Invest 2003, 83:387396).
\end{abstract}

erm-line mutations in the $B R C A 1$ gene are a
common cause of inherited breast and ovarian
cancer. BRCA1 has been suggested to play a role in
maintaining genetic stability through functions involv-

DOI: 10.1097/01.LAB.0000060030.10652.8C

Received December 16, 2002.

This study was supported by grants from the Swedish Cancer Society, the Knut and Alice Wallenberg Foundation through the SWEGENE consortium, the King Gustav V:s Jubilee Foundation, Mrs. Berta Kamprads Foundation, Gunnar Arvid \& Elisabeth Nilsson Foundation, the Hospital of Lund Foundations, the Crafoord Foundation, the Royal Physiographical Society, the CTRF Foundation, the Wenner-Gren Foundation, the Satakunta Cultural Foundation, Finnish Medical Association, Medical Research Fund of Tampere University Hospital, the Finnish Cancer Society, and the Nordic Cancer Union.

Inquiries about the cell line should be addressed to Stina Oredsson, Department of Cell and Organism Biology, Lund University, Lund, Sweden. E-mail: stina.oredsson@cob.lu.se.

Address reprint requests to: Dr. Oskar T. Johannsson, Department of Medical Oncology, University Hospital of Iceland, Reykjavik, Iceland. E-mail: oskarjoh@landspitali.is ing DNA damage repair and cell cycle control (reviewed in Venkitaraman, 2002; Welcsh et al, 2000; Zheng et al, 2000). Most of the insights into the functions of the BRCA1 protein have been gained from studies of mice by use of gene targeting and studies of altered mouse embryonic cells. Although these studies have gained important insights into the functions of the BRCA1 protein in mice, it is still unclear how well these observations are applicable to the situation in humans. Mice heterozygous for BRCA1 mutations are not predisposed to develop breast or ovarian cancer or any other cancer, suggesting that the function and role of the BRCA1 protein may not be the same in mice and humans (Hakem et al, 1996; Liu et al, 1996; Ludwig et al, 1997). In studies using conditional mutant mouse strains, the mice do develop mammary cancers, although at a lower incidence and relatively late in life (Xu et al, 1999). Their relevance to the human situation remains to be elucidated, although some studies report a strikingly similar histopathology in BRCA1 null breast tumors from mice and humans (Dennis, 1999; Xu et al, 1999). 
Studies of the function of BRCA1 in humans have been limited because of lack of suitable models that resemble the in vivo condition. Hampered by a lack of $B R C A 1$ null ( $-/-)$ cells, most studies are conducted on modified cell lines that harbor normal BRCA1 genes. To date, only one BRCA1 mutated breast cancer cell line (HCC1937) is available (Tomlinson et al, 1998). Here we report the establishment and characterization of a novel xenograft, L56Br-X1, established from a breast cancer lymph node metastasis from a BRCA1 germ-line mutation (1806C > T; Q563X) carrier, as well as a cell line, $\mathrm{L} 56 \mathrm{Br}-\mathrm{C} 1$, derived from the xenograft.

\section{Results}

\section{Preparation of the Xenograft and Cell Line}

A serially transplantable subcutaneous xenograft, designated L56Br-X1, was established from a lymph node metastasis. The tumor take rate after generation 7 was $80 \%$ to $85 \%$. The mean tumor-doubling rate was 13 days in generation 11. No macroscopically detectable metastases have been found in any xenograft mice so far.
A breast cancer cell line, designated L56Br-C1, was established from tumor tissue derived from xenograft generation 6 . The cells grow as an adherent monolayer to confluence, with a population doubling time of approximately 27 hours during exponential growth. The cell line displays a constant rate of cell death (detached and floating cells) with approximately $4 \%$ of the cells found in the pre-G1 region as determined by flow cytometry (Hegardt et al, 2002). The L56BR-C1 cells have undergone several passages and show continuous growth, even after recovery from cryopreservation. L56BR-C1 shows a malignant-like irregular growth pattern in three-dimensional gels, which is in line with the histopathology seen in L56BR xenografts (data not shown). Injection of L56-BR-C1 cells subcutaneously in nude mice leads to formation of new xenograft tumors.

\section{Analysis of the BRCA1 Gene Status}

The presence of a germ-line mutation in exon 11 of BRCA1, 1806C > T; GIn563Stop, was verified in blood cells from the patient and was shown to be retained in hemizygous state in the primary tumor tissue as well

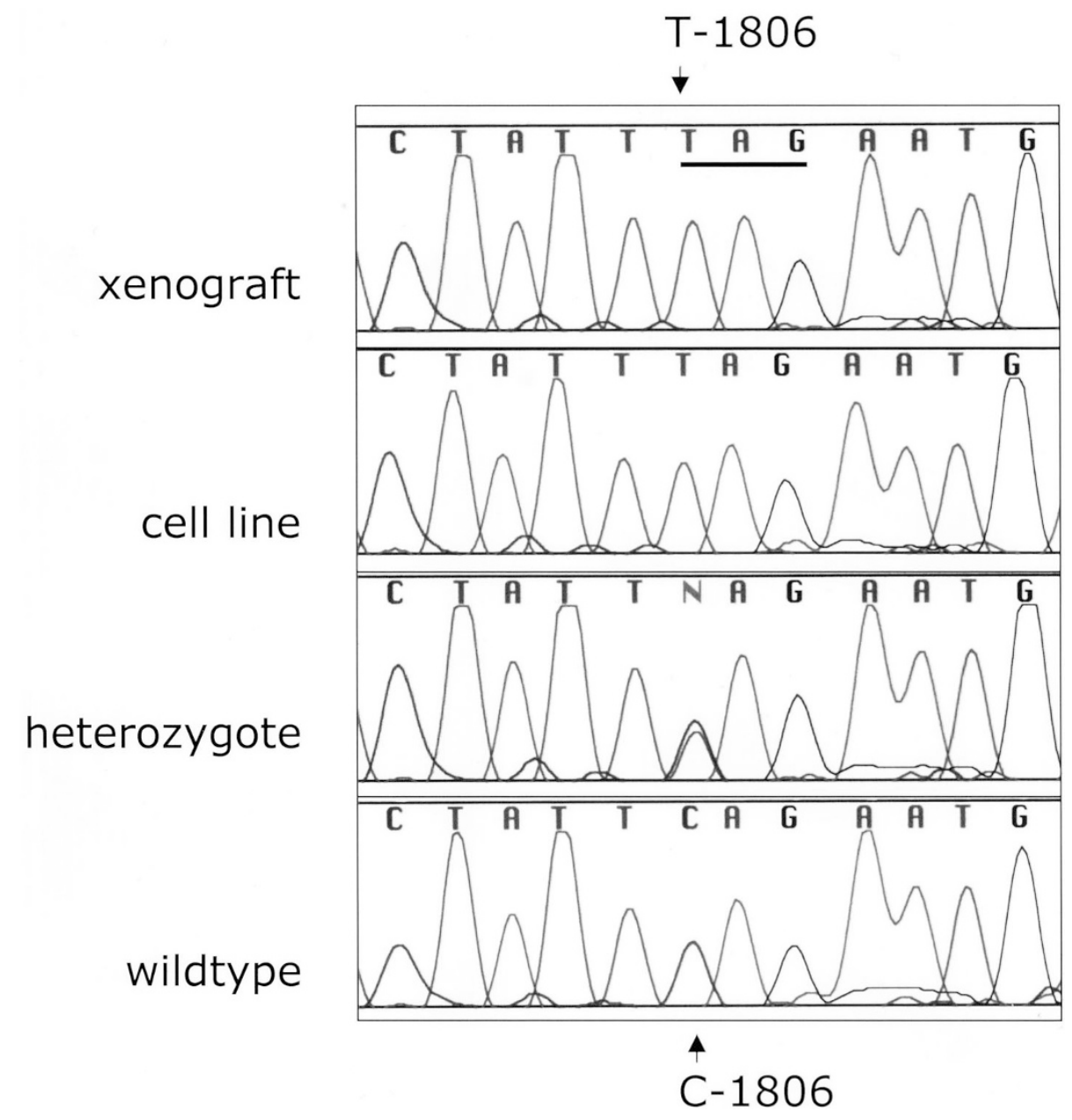

Figure 1.

Sequence graph of the region surrounding the BRCA1 1806C/T mutation in the xenograft (1806-T hemizygous), cell line (1806-T hemizygous), germ-line from the patient (1806C/T heterozygous) and germ-line from a noncarrier (homozygous for 1806-C). 
as in the xenograft and cell line (Fig. 1). The mutation is a known Swedish founder mutation (Johannsson et al, 1996) that has also been found elsewhere in Europe and North America. Fluorescence in situ hybridization (FISH) analysis with probes to BRCA1 and chromosome 17 centromere showed a single copy of each, indicating monosomy of chromosome 17 in the xenograft and, hence, a loss of the wild-type BRCA1 allele (data not shown).
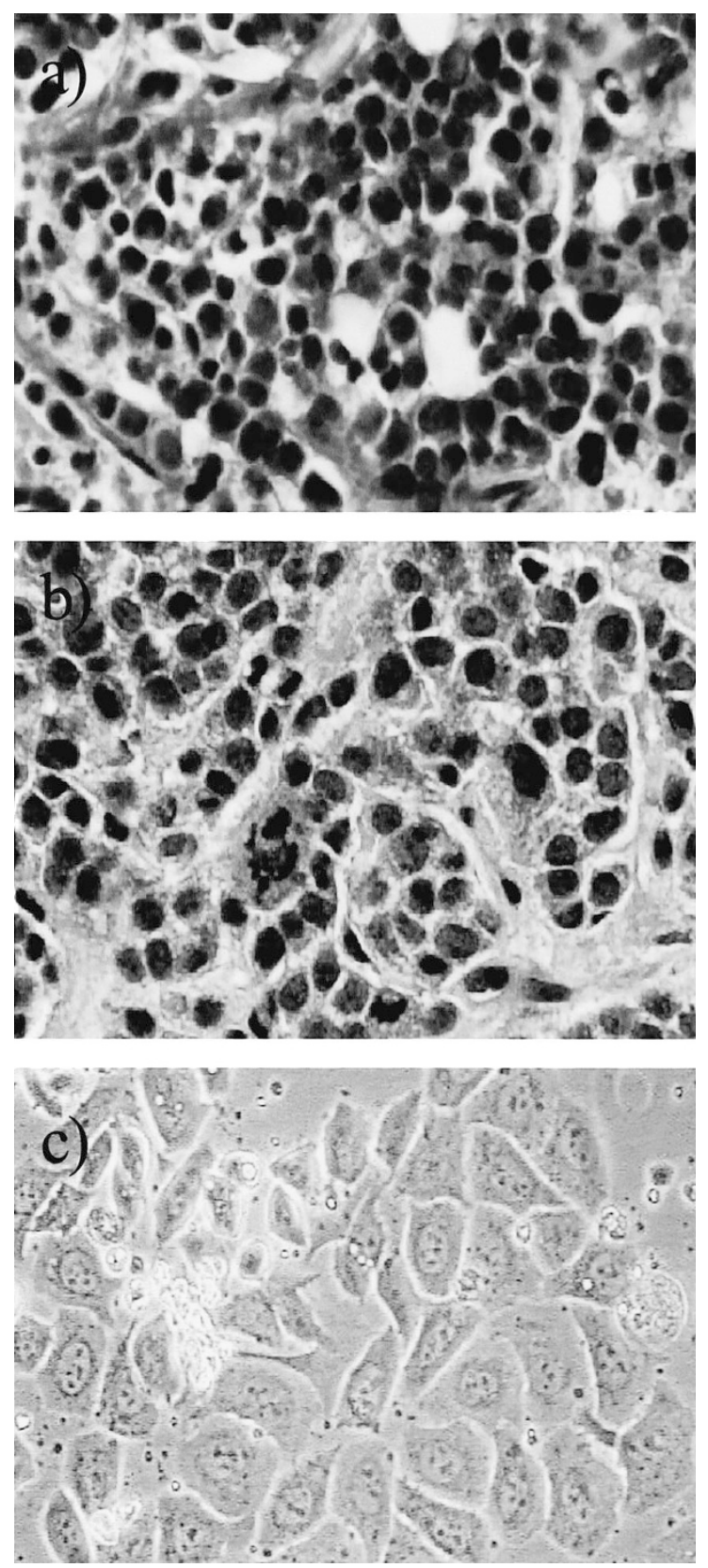

Figure 2.

Histologic and cytologic features of primary tumor (a), xenograft (b), and the cell line (c) demonstrate that the cytologic and architectural features of the carcinoma cells are preserved in the xenograft and cell line (a and $b$, hematoxylin and eosin staining; c, phase contrast micrograph). Original magnification, $\times 450$.

\section{Histopathology}

Histologic examination of the primary cancer, the lymph node metastasis, and xenograft tumors (Fig. 2) revealed a poorly differentiated adenocarcinoma with no ductal differentiation. The growth pattern was characterized by pushing border type of tumor margins and small foci of necrosis at the tumor center. No significant change has occurred with regard to histopathologic features during the evolution of the xenograft thus far. Both the primary cancer and xenograft and cell line tumor cells contain multinucleated cells. The cell line has the appearance of small- to mediumsized epithelioid cells with similar variations in nuclear size as the primary tumor (Fig. 2). No cytoplasmic vacuoles, such as those described for the BRCA1 mutated cell line HCC1937 (Tomlinson et al, 1998), were noted.

\section{Expression of BRCA1 mRNA and BRCA1 Protein}

The xenograft expressed the full-length mutant BRCA1 mRNA, as well as the isoforms $\Delta 9,10$, $\Delta 9,10,11 \mathrm{~b}$, and $\Delta 11 \mathrm{~b}$ (Fig. 3). The mRNA expression of the xenograft was similar to $\mathrm{HBL}-100$ cell line (a control with wild-type BRCA1), although the observed bands were less prominent. No PCR products were obtained in any of the negative PCR controls (reverse transcriptase negative and mouse cDNA samples, data not shown).

Whereas HBL-100 control cells expressed a BRCA1 protein of $220 \mathrm{kd}$ (corresponding to the full-length BRCA1 protein) (Chen et al, 1996), detected by immunoprecipitation and Western blotting both with antibodies to $\mathrm{N}$ - and $\mathrm{C}$-terminal parts of the BRCA1 protein, no traces of BRCA1 proteins were detected in the xenograft (Fig. 4). No bands at 100 to $110 \mathrm{kd}$, corresponding to the variant lacking most of exon 11 (including C-1806), were observed either in xenograft or in control HBL-100 cells (data not shown). Moreover, no evidence of truncated protein products was detected with the N-terminal MS110 BRCA1 antibody in the xenograft (Fig. 4b).

\section{Gene Expression Profiling}

Microarray analysis revealed different correlations between gene expression profiles. Similarity of gene expression profiles were assessed by calculating Pearson correlation coefficients between data sets of intensity ratios from various samples (Table 1). A cluster analysis of expression profiles is also shown in Figure 5. Highest correlation was observed between the primary tumor, the lymph node metastasis, and an early generation of the xenograft (generation 4). Slightly lower correlation was observed when the primary and lymph node tumors were compared with a later generation xenograft (generation 22). There was a higher similarity between any of the xenograft generations or the cell line and the metastasis (from which the xenograft is derived) compared with correlation to the primary tumor. The cell line showed similar correlation to either xenograft generation or the lymph node 


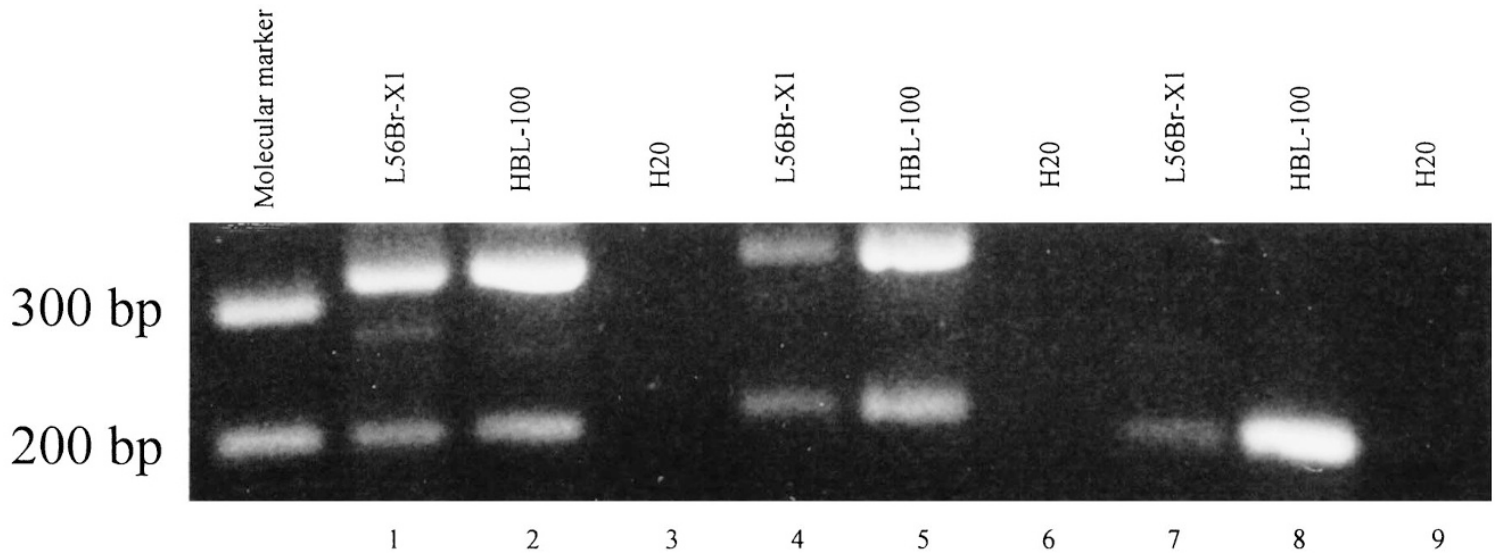

Figure 3.

Expression of BRCA1 mRNA splice variants in L56Br-X1 xenograft and in wild-type control (breast cancer cell line HBL-100). Lanes 1 to 3 show the $324-\mathrm{bp}$ PCR product, which corresponds to the full-length BRCA1 mRNA. A shorter product of $200 \mathrm{bp}$ corresponds to the $\triangle 9,10$ BRCA1 mRNA. Lanes 4 to 5 represent the 339 and 215-bp products corresponding to the BRCA1 mRNA isoforms $\triangle 11 \mathrm{~b}$ and $\Delta 9,10,11 \mathrm{~b}$, respectively. Lanes 7 to 9 show the 199-bp product, which corresponds specifically to the $\triangle 11 \mathrm{~b} B R C A 1$ mRNA variant.

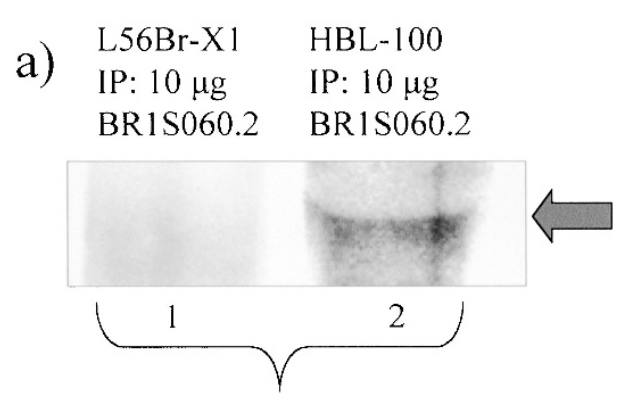

WB: MS110

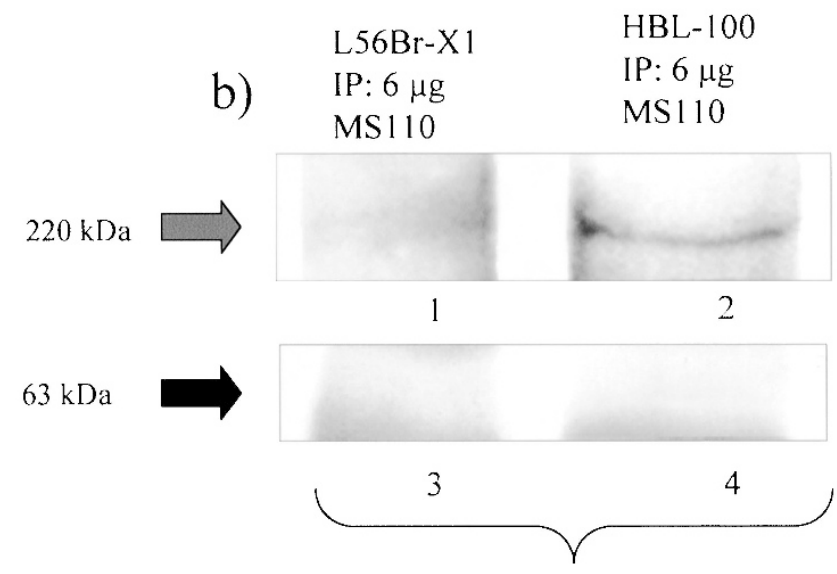

WB: MS110

\section{Figure 4.}

Expression of BRCA1 protein by immunoprecipitation and Western blotting using the mAb MS-110. a, Lanes 1 and 2 show L56Br-X1 and the wild-type control (breast cancer cell line HBL-100), respectively, where BR1S060.2 (10 $\mu \mathrm{g})$ was used to immunoprecipitate BRCA1 proteins from the lysates. B, Lanes 1 and 2 show $\mathrm{L} 56 \mathrm{Br}-\mathrm{X} 1$ and the wild-type control (breast cancer cell line HBL-100), respectively, where MS110 $(6 \mu \mathrm{g})$ was used to immunoprecipitate BRCA1 proteins from the lysates. Gray arrows indicate the position of BRCA1 $220 \mathrm{kd}$. Lanes 3 and 4 show L56Br-X1 and the control HBL-100 cell line at the position of 63 kd (black arrow), where the truncated BRCA1 protein of 563 amino acids resulting from the mutation Q563X is expected to migrate.

Table 1. Correlation Coefficients for Comparison of Gene Expression Profiles in a Primary Breast Tumor and Its Axillary Lymph Node Metastasis, a Xenograft Derived from the Metastasis and Passed in Nude Mice 4 (Xeno 4) and 22 (Xeno 22) Generations, Respectively, and a Cell Line (L56Br-Cl) Derived from the Xenograft (Generation 6).

\begin{tabular}{rccccc}
\hline & Prim & LN-met & Xen04 & Xeno22 & L56Br-Cl \\
\hline Prim & 1.0000 & & & & \\
LN-met & 0.8365 & 1.0000 & & & \\
Xen04 & 0.7589 & 0.8016 & 1.0000 & & \\
Xeno22 & 0.6241 & 0.6627 & 0.7963 & 1.0000 & 1.0000 \\
L56Br-C1 & 0.4501 & 0.5420 & 0.5411 & 0.5364 & \\
\hline
\end{tabular}

prim, primary tumor; LN-met, lymph node metastasis.

Pearson correlation (obs $=3295)$. 


\section{$\underline{\text { Sample }}$}

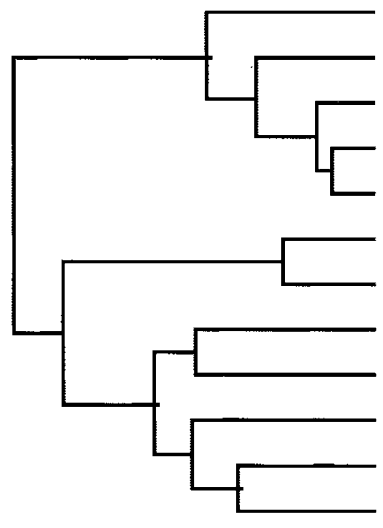

L56Br-C1 cell line

Xenograft, generation 22

Xenograft generation 4

Node metastasis

Primary tumor

BT-474 (cell line)

BT-474 (cell line)

Sporadic tumor 1

Sporadic tumor 2

Sporadic tumor 3

Sporadic tumor 4

Sporadic tumor 5

Figure 5.

Cluster analysis of gene expression profiles from L56BR-C1 and the xenograft demonstrates their close relationship to the parental tumor samples and dissimilarity from unrelated sporadic tumors or the reference BT-474 cell line.

metastasis but slightly less correlation with the primary tumor. A gene expression profile of the primary tumor has been published in a previous study (Hedenfalk et al, 2001).

\section{Tumor Biological Characteristics}

Immunostaining of the primary tumor and the xenograft revealed no differences, either between the primary tumor and the xenograft or between different xenograft generations (generations 4, 6, and 9). The primary tumor and the different xenograft generations are immunohistochemically negative for estrogen receptor, progesterone receptor, human epidermal growth factor receptor 2 (HER-2), and epidermal growth factor receptor with $0 \%$ positive cells (data not shown). The xenograft was also negative for keratin 8 immunoreactivity. The proliferation antigen $\mathrm{Ki} 67$ and TP53 were strongly positive with $60 \%$ to $70 \%$ and $90 \%$ to $100 \%$ positive cells, respectively (data not shown). Sequence analysis of TP53 in the primary tumor revealed a somatic nucleotide substitution in exon 6 at position 644, AGT to ATT, giving rise to a missense mutation, Ser215lle. This mutation was present also in the xenograft and cell line (data not shown).

DNA flow cytometry of the primary tumor and the lymph node metastasis revealed a hypodiploid tumor with a DNA index of 0.85 . This DNA index remained stable throughout the establishment of the xenograft. FISH analyses of BRCA1 (17q21) and TP53 (17p13) and chromosome 17 centromere in the xenograft revealed the presence of a single copy of each, indicating monosomy of chromosome 17. No relative gene copy number change was noticed regarding BRCA2 by FISH. Additional evidence to support the hypodiploid status is an apparent monosomy of the chromosome 6 (centromere probe). Flow cytometric analysis of the cell line revealed it to be aneuploid with a DNA index of 1.75 , indicating that it has developed from a polyploidization of the primary L56BR-X1 tumor.

\section{Karyotype}

Cytogenetic analysis of the cell line revealed a complex karyotype with numerous marker chromosomes. The chromosome number varied between 63 and 66 . With the help of spectral karyotyping, a complete karyotype was generated leaving no marker chromosomes of unknown origin (Table 2). Most of the translocations were unbalanced and detected also by comparative genomic hybridization ( $\mathrm{CGH}$; Table 2). The CGH aberrations have remained the same from the primary tumor throughout the establishment of the xenograft with no major or minor new events becoming visible. The cell line reveals an almost identical pattern of aberrations by $\mathrm{CGH}$ analysis as the xenograft (Fig. 6).

\section{Discussion}

We report here the establishment of a breast cancer xenograft and cell line derived from a BRCA1 germline mutation carrier. As confirmed by $\mathrm{FISH}$, these cells are hemizygous for $B R C A 1$, ie, only the mutant allele is present as a result of monosomy of chromosome 17. The BRCA1 mutation (1806C $>$ T) leads to a predicted translation termination at amino acid 563 (of 1863 in the wild-type protein), before the nuclear localization sequences, the proposed interaction site with the MRE11/RAD50/Nbs1 protein complex, as well as the BRCA1 C-Terminal (BRCT) domains (reviewed in Venkitaraman, 2002). Thus, if expressed, the truncated BRCA1 protein should have lost its nuclear localization and most or all of its functions in DNA repair and transactivation. Alternatively, expression of a previously described BRCA1 splice variant $(\Delta 11 \mathrm{~b})$, lacking most of exon 11 and including the truncating mutation (1806C $>$ T), would theoretically allow expression of a shorter BRCA1 protein that retains the $\mathrm{N}$ - and C-terminal epitopes recognized by the antibodies used in the present study. This BRCA $1-\Delta 11 \mathrm{~b}$ protein is probably cytoplasmic as a result of lack of nuclear 
Table 2. Karyotype Based on Spectral Karyotyping and G-banding, and CGH Results of the Cell Line L56Br-CI
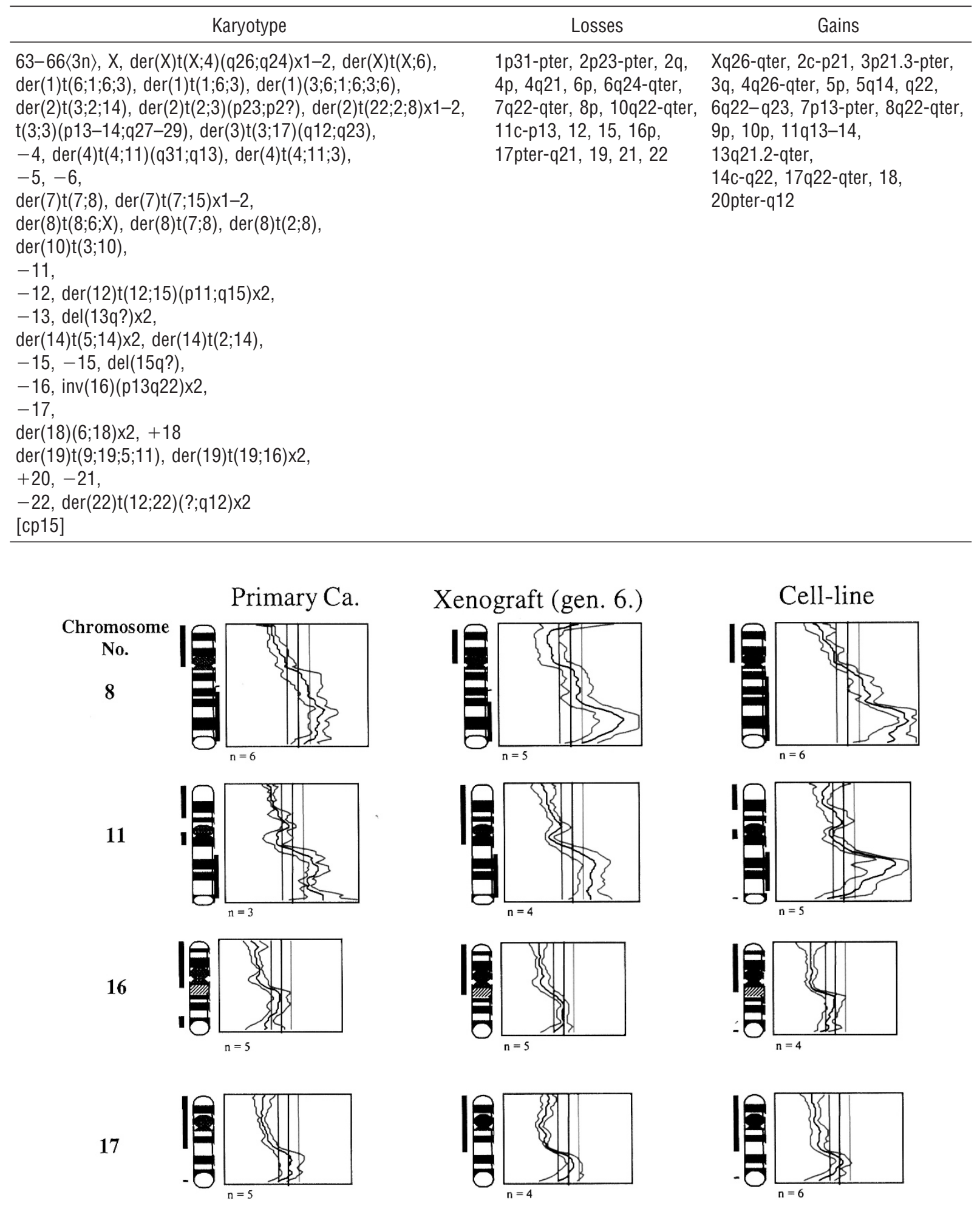

Figure 6.

Comparison of comparative genomic hybridization changes for chromosomes $8,11,16$, and 17 between primary cancer, xenograft generation 6 , and cell line.

localization sequences, and, unlike full-length protein, overexpression of the variant protein is nontoxic and endured by the cells (Wilson et al, 1997). However, despite expression of a full-length BRCA1 transcript and the $\Delta 11 \mathrm{~b}$ mRNA isoform, both obviously having escaped nonsense-mediated decay, no traces of BRCA1 protein could be found by immunoprecipitation or Western blotting in xenograft cells, although we cannot exclude the presence of proteins at levels below detection limits. 
The presence of numerous chromosomal aberrations is a documented feature of BRCA1 tumors, which are also grossly aneuploid by DNA content (Johannsson et al, 1997; Tirkkonen et al, 1997). Some of the chromosomal aberrations found, such as the del $1 q 42,+7$, and amplification of the $11 q 13$ region, are commonly found also in sporadic breast cancer, whereas others, eg, -4 and -5 , are more typical of BRCA1-associated breast tumors (Tirkkonen et al, 1997). However, despite the extensive genetic instability, the $\mathrm{L} 56 \mathrm{Br}-\mathrm{X} 1$ xenograft and cell line have remained stable with regard to the genotype and tumor biologic features during their establishment and progression. Possibly, the cells have kept some apoptotic mechanisms in response to severe genetic aberrations, as evident by the constant detachment of dead cells into the medium. This suggests that the clinically detected tumor had already reached a plateau in its genetic evolution, which was not altered even when the cells were established and grown for a number of passages as a xenograft or in culture. In this respect the BRCA1 tumors seem not to differ from sporadic cancer, the metastases of which usually retain the characteristics of the primary tumor despite a long latency before the onset of metastases (Kuukasjärvi et al, 1997a, 1997b). Gene expression profiling supports the genomic findings. Correlation coefficients indicate a high similarity between xenograft generation 4 and the lymph node metastasis and a somewhat lower similarity when comparing xenograft generation 4 with the primary tumor. This may reflect that the xenograft was established from the axillary lymph node metastasis. The same pattern is observed when investigating xenograft generation 22; however, the similarity between the latter and the primary tumor/metastasis is lower than that of xenograft generation 4, which may illustrate an ongoing progression of the xenograft lineage. Interestingly, when comparing gene expression profiles from the cell line with either the primary tumor or xenograft generations 4 or 22, the correlation is similar with a slightly decreasing trend. This may indicate that, whereas the xenograft lineage seems to divert away from the primary tumor/metastasis, the cell line preserves a gene expression profile that is common for the primary tumor, metastasis, and different xenograft generations.

The xenograft carries the hallmarks of a BRCA1associated cancer, being a high-grade invasive ductal carcinoma, lacking expression of estrogen and progesterone receptors and HER-2 oncoprotein. The cells were also negative for the expression of keratin 8 , which is an uncommon feature in breast cancer in general but characteristic of BRCA1 tumors (Hedenfalk et al, 2001). Gene expression profiling further indicates that both the xenograft and the cell line are similar to the primary tumor and suggests that not only the genotype but also the phenotype can remain remarkably stable despite a drastic change in the growth environment (in vivo versus xenograft versus in vitro). Moreover, an earlier study showed that the primary tumor, from which the lymph node metastasis and xenograft are derived, has a similar gene expres- sion profile as other BRCA1 tumors, clearly distinguished from $B R C A 2$ and sporadic breast tumors (Hedenfalk et al, 2001). Accordingly, On the basis of histopathologic, genotypic, and phenotypic characterization, we conclude that the L56Br-X1 and L56Br-C1 closely mimic BRCA1-associated breast cancer in vivo. Thus, they compose a useful model system for studies of the pathogenesis and treatment of BRCA1induced human breast cancer.

\section{Materials and Methods}

The tumor tissue was derived from a patient who belonged to a Swedish family previously described to carry a BRCA1 germ-line mutation (Johannsson et al, 1996). Both breast and ovarian cancers are found among the family members. At the age of 46 , the patient received a diagnosis and was surgically treated for a stage I ductal invasive breast cancer followed by local radiotherapy but no chemo- or hormonal therapy. She developed a contralateral primary breast cancer with axillary lymph node metastases (T1N1M0) at the age of 53 and underwent two operations, a primary segmental resection and a subsequent axillary dissection. Tumor tissue obtained during the axillary dissection was used to establish primary growths. Distant metastases were diagnosed in lungs, liver, and the skeleton 5 months after completion of adjuvant dose-escalated chemotherapy and radiotherapy. She did not respond to further chemotherapy and died 18 months after diagnosis as a result of symptoms caused by multiple metastases.

\section{Preparation of the Xenograft and Cell Line}

Informed consent was obtained from the patient before the study. Two tumor fragments (each measuring $2 \times 2 \mathrm{~mm}$ ) were placed subcutaneously in immunodeficient Balb/c nude mice (nu/nu). Eighteen months after the primary establishment, the xenografts had undergone 11 subsequent generations. Specimens of the axillary metastasis (approximately $1 \mathrm{~mm}$ in diameter) obtained from primary surgery were also placed in culture dishes, but all primary cultures failed. However, cultures using tumor tissue from the xenograft generation 6 were successful and gave rise to a permanent cell line. The culture medium used consisted of RPMI 1640 media with 10 mM HEPES, fetal bovine serum (10\%), glucose (4.5 g/L), pyruvic acid $(0.11 \mathrm{~g} / \mathrm{L})$, and antibiotics (penicillin and streptomycin; incubation at $37^{\circ} \mathrm{C}$ in an atmosphere of $5 \% \mathrm{CO}_{2}$ in air). The cells were routinely passed once a week, and the medium was changed twice in between. For testing tumor formation of the cell line, approximately 2 million cells have been injected subcutaneously in nude mice.

\section{Mutation Analysis}

The presence of a BRCA1 germ-line mutation was known before the operation (Johannsson et al, 1996). The mutation was discovered by the presence of an aberrantly short band upon protein truncation test of 
exon 11 of the BRCA1 gene and verified by direct sequencing as described before (Johannsson et al, 1996). Direct sequencing was also used to investigate the entire coding region of the TP53 gene.

\section{Pathologic Examination and Tumor Biologic Analyses}

The two primary tumors from both breasts, as well as the xenograft, were examined using standard histopathologic techniques and the World Health Organization's histopathologic classification. Immunohistochemical stainings were performed using commercially available antibodies to the estrogen receptor (clone 1D5; Dako, Glostrup, Denmark), progesterone receptor (clone hPRa2+hPRa3; Neomarkers), HER-2 oncoprotein (clone NCL-B11; Novocastra, New Castle, UK), TP53 (clone DO-7; Novocastra), Ki67 (clone MM-1; Novocastra), epidermal growth factor receptor (clone EGFR.113; Novocastra), and keratin 8 (5D3; Novocastra). DNA flow cytometry was done as previously described (Johannsson et al, 1997). Dualcolor FISH was performed using probes for chromosome 17 centromere, TP53, BRCA1, and BRCA2 on nuclei isolated from tumor samples from the primary tumor, as well as on different xenograft generations as previously described (Staff et al, 2000).

\section{Expression of BRCA1 mRNA}

Total RNA from the xenograft and HBL-100 breast cancer cell line (with wild-type BRCA1; obtained from the American Type Culture Collection and cultured according to the recommended conditions) was isolated using Sigma GenElute Mammalian Total RNA Kit (Sigma-Genosys, United Kingdom) according to the manufacturer's instructions. An aliquot of $3 \mu \mathrm{g}$ of total RNA was used for the first-strand cDNA synthesis with Superscript II reverse transcriptase and random hexamer primer according to the manufacturer's instructions (Invitrogen, Life Technologies). Parallel cDNA synthesis reactions with no added reverse transcriptase were performed. The following primers were used for the PCR amplification of BRCA1 cDNA: 5'-ACAAAGCAGCGGATACAACC-3' (Primer 1, sense primer in exon 8), 5'-ACATGGCTCCACATGCAAG-3' (Primer 2, antisense primer in exon 11), 5'-GCAGTCTTCAGAGACGCTTG-3' (Primer 3, antisense in exon 12), and 5'GGATGAAATCAGTTTGGATTCTG-3' (Primer 4, sense primer in exon 10). Primers 1 and 2 were designed to amplify 324- and 200-bp products corresponding to the full-length and $\triangle 9,10 B R C A 1$ mRNAs, respectively. Primers 1 and 3 were designed to amplify 339- and 215-bp products corresponding to the $\Delta 11 \mathrm{~b}$ and $\Delta 9,10,11 \mathrm{~b} B R C A 1 \mathrm{mRNAs}$, respectively. Primers 3 and 4 were designed to amplify a product of $199 \mathrm{bp}$, which corresponds to the $\triangle 11 \mathrm{~b} B R C A 1$ mRNA. The primers used in the study are modified from the previously described primers designed to amplify the full-length BRCA1 and its common splice variants (Orban and Olah, 2001).

The PCR mixture $(25 \mu \mathrm{l})$ contained $0.3 \mu \mathrm{g}$ of cDNA template, $10 \mathrm{~mm}$ Tris- $\mathrm{HCl}\left(\mathrm{pH} 8.8\right.$ at $\left.25^{\circ} \mathrm{C}\right), 1.5 \mathrm{~mm}$
$\mathrm{MgCl}_{2}, 50 \mathrm{~mm} \mathrm{KCl}$ and $0.1 \%$ Triton X-100, $0.2 \mathrm{~mm}$ of dNTPs, $0.1 \mu \mathrm{m}$ of sense and antisense primer, and 2 units of Dynazyme Taq polymerase (Finnzymes, Helsinki, Finland). The PCR reactions were carried out in PTC-100 Programmable Thermal Controller (PeltierEffect Cycling, MJ Research, Inc.). The PCR reaction consisted of 3 minutes at $95^{\circ} \mathrm{C}$, followed by 29 cycles of 1 minute at $94^{\circ} \mathrm{C}, 40$ seconds at $56^{\circ} \mathrm{C}, 1$ minute at $72^{\circ} \mathrm{C}$, and finally followed by one cycle for 5 minutes at $72^{\circ} \mathrm{C}$. The PCR products were analyzed on $1.5 \%$ agarose gels.

\section{Expression of BRCA1 Protein by Immunoprecipitation and Western Blot}

For collecting both cytoplasmic and nuclear protein lysates, 50 to $100 \mathrm{mg}$ of freshly frozen xenograft tumor sample was treated with 250 to $500 \mu \mathrm{l}$ of ice-cold lysis buffer containing $0.25 \mathrm{M} \mathrm{NaCl}, 0.1 \% \mathrm{NP} 40,50 \mathrm{~mm}$ HEPES, and 5 mm EDTA with freshly added cocktail of protease inhibitors (10 mM dithiothreitol, $1 \mu \mathrm{g} / \mathrm{ml}$ aprotinin, $1 \mu \mathrm{g} / \mathrm{ml}$ leupeptin, and $0.2 \mathrm{~mm}$ phenylmethylsulfonyl fluoride). Xenograft sample was homogenized with tissue homogenizer at maximum speed three times for 5 seconds. HBL-100 cells were treated with the same ice-cold lysis buffer with protease inhibitors. Both samples were then incubated on ice for 30 minutes, passed through a 21-G needle, and cleared from insoluble cellular debris by centrifugation. Protein concentrations were measured using the BIO-RAD DC Protein Assay (BIO-RAD Laboratories, Hercules, CA), and lysates were stored at $-70^{\circ} \mathrm{C}$.

A total of $500 \mu \mathrm{g}$ of xenograft and HBL-100 protein lysates were immunoprecipitated with both $10 \mu \mathrm{g}$ of Hybritech BR1S060.2 C-terminal BRCA1 antibody (Hybritech Inc.) and $6 \mu \mathrm{g}$ of MS110 N-terminal BRCA1 antibody (Oncogene Research Products). The following day, $20 \mu$ l of Protein G PLUS-Agarose (Santa Cruz Biochemicals, Santa Cruz, California) was added for overnight incubation at $4^{\circ} \mathrm{C}$. Then immunoprecipitates were collected by centrifugation and washed with lysis buffer, resuspended in $30 \mu$ l of $2 \times$ SDS loading buffer, run on a $5.5 \%$ to $6.5 \%$ SDSpolyacrylamide gel, and transferred to nitrocellulose membrane (BIO-RAD Laboratories). The immunoblot was blocked in 4\% dry milk in Tris-buffered saline and $0.1 \%$ Tween. The membrane was immunoblotted with primary antibody BRCA1 MS110 (Oncogene Research Products). The blot was washed in $4 \%$ milk in Trisbuffered saline and $0.1 \%$ Tween and incubated with horseradish peroxidase-conjugated secondary antimouse antibody (Calbiochem, San Diego, California). The blot was developed by SuperSignal West Pico Chemiluminescent Substrate (Pierce).

\section{Gene Expression Profiling by cDNA Microarrays}

Total RNA was extracted from frozen tissue and cells using Trizol (InVitrogen, Carlsbad, California) followed by RNeasy (Qiagen). A common human RNA control (Stratagene) was used for all hybridizations. For each hybridization, $25 \mu \mathrm{g}$ of sample RNA and $25 \mu \mathrm{g}$ of 
common control RNA were used to generate aminoallyl-modified cDNA and differentially labeled by coupling Cy 3 or Cy 5 molecules to the cDNA according to the manufacturer's recommendations (CyScribe Post-Labeling Kit; Amersham Pharmacia Biotech). A hybridization solution was prepared by combining labeled cDNA, $20 \mu \mathrm{l}$ of Cot- 1 DNA ( $1 \mathrm{mg} / \mathrm{ml}), 3 \mu \mathrm{l}$ of Poly $\mathrm{dA}_{40-60}(4 \mathrm{mg} / \mathrm{ml})$, and $1.5 \mu$ l of yeast tRNA (4 $\mathrm{mg} / \mathrm{ml}$ ), dried down in a speed-vac and resuspended in $130 \mu \mathrm{l}$ of DIG-Easy (Roche)/1\% BSA (Sigma). The hybridization solution was added to a prehybridized (1\% BSA), microarray slide, incubated at $42^{\circ} \mathrm{C}$ for 17 hours, and washed with wash 1 ( $2 \times$ SSC, $0.1 \%$ SDS), wash 2 ( $1 \times \mathrm{SSC})$, and wash 3 ( $0.1 \times \mathrm{SSC})$ and subsequently dried by centrifugation using a swingout rotor.

Arrays were produced using PCR-amplified DNA targets from Sequence Verified Human cDNA Clones (ResGen, Invitrogen Corporation). PCR products were verified by agarose gel electrophoresis and purified using size-exclusion filtration (Millipore, Bedford, MA). After purification, target was recovered in water and adjusted to $50 \%$ DMSO. Target DNA was printed on amino-silane coated glass slides (UltraGAPS; Corning) using a MicroGrid2 equipped with MicroSpot10K pins (BioRobotics).

Arrays were scanned (Agilent DNA Microarray Scanner; Agilent Technologies), images were analyzed (Genepix Pro 3.0; Axon Instruments, Burlingame, California), and Сy3 and Cy5 intensities corrected for background were calculated using median feature and median local background intensities. Within-array normalization was done using an implementation of the intensity-dependent normalization based on a lowest fit as previously described (Yang et al, 2002) and provided in the BioArray Software Environment (Saal et al, 2002). Subsequent filter steps were performed within the BioArray Software Environment to select for probes designated to individual UniGene clusters (www.ncbi.nlm.nih.gov/UniGene/), with a minimum intensity in both channels and presence in all hybridizations so that data from 3295 probes remained. Pearson correlation coefficients were calculated using STATA.

\section{Cytogenetic Analyses}

The cultured cells were harvested (trypsinized) after exposure to colcemid for 4 hours, followed by a hypotonic shock in $0.05 \mathrm{M} \mathrm{KCl}$, and fixation in methanol acetic acid (3:1). G-banding of chromosomes was obtained with Wright's stain. The clonality criteria and karyotype description followed the recommendations of Mitelman (1995). Spectral karyotyping was done according to the manufacturer's instructions (SKY kit; Applied Spectral Imaging, Israel). CGH was performed as previously described (Rennstam et al, 2001) on genomic DNA isolated from the primary tumor and xenograft generation 6 , as well as of the cell line.

\section{Acknowledgments}

We thank Kristina Boll and Margareta Olsson for work with the xenograft and cell line and Ulla Johansson and Therese Sandberg for BRCA1 and TP53 mutation analysis.

\section{References}

Chen Y, Farmer AA, Chen CF, Jones DC, Chen PL, and Lee WH (1996). BRCA1 is a 220-kDa nuclear phosphoprotein that is expressed and phosphorylated in a cell cycle-dependent manner. Cancer Res 56:3168-3172.

Dennis C (1999). Branching out with BRCA1. Nat Genet 22:10.

Hakem R, de la Pompa JL, Sirard C, Mo R, Woo M, Hakem A, Wakeham A, Potter J, Reitmair A, Billia F, Firpo E, Hui CC, Roberts J, Rossant J, and Mak TW (1996). The tumor suppressor gene Brca1 is required for embryonic cellular proliferation in the mouse. Cell 85:1009-1023.

Hedenfalk I, Duggan D, Chen Y, Radmacher M, Bittner M, Simon R, Meltzer P, Gusterson B, Esteller M, Kallioniemi OP, Wilfond B, Borg A, and Trent J (2001). Gene-expression profiles in hereditary breast cancer. N Engl J Med 344:539548.

Hegardt C, Johannsson O, and Oredsson SM (2002). Rapid caspase-dependent cell death in a human breast cancer cells induced by the polyamine analogue N1, N11diethylnorspermine. Eur J Biochem 269:1033-1039.

Johannsson O, Ostermeyer EA, Hakansson S, Friedman LS, Johansson U, Sellberg G, Brondum-Nielsen K, Sele V, Olsson $\mathrm{H}$, King $\mathrm{M}-\mathrm{C}$, and Borg A (1996). Founding BRCA1 mutations in hereditary breast and ovarian cancer in southern Sweden. Am J Hum Genet 58:441-450.

Johannsson OT, Idvall I, Anderson C, Borg A, Barkardottir RB, Egilsson V, and Olsson H (1997). Tumour biological features of BRCA1-induced breast and ovarian cancer. Eur $\mathrm{J}$ Cancer 33:362-371.

Kuukasjärvi T, Karhu R, Tanner M, Kahkonen M, Schaffer A, Nupponen N, Pennanen S, Kallioniemi A, Kallioniemi OP, and Isola J (1997a). Genetic heterogeneity and clonal evolution underlying development of asynchronous metastasis in human breast cancer. Cancer Res 57:1597-1604.

Kuukasjärvi T, Tanner M, Pennanen S, Karhu R, Kallioniemi OP, and Isola J (1997b). Genetic changes in intraductal breast cancer detected by comparative genomic hybridization. Am J Pathol 150:1465-1471.

Liu CY, Flesken-Nikitin A, Li S, Zeng Y, and Lee WH (1996). Inactivation of the mouse Brca1 gene leads to failure in the morphogenesis of the egg cylinder in early postimplantation development. Genes Dev 10:1835-1843.

Ludwig T, Chapman DL, Papaioannou VE, and Efstratiadis A (1997). Targeted mutations of breast cancer susceptibility gene homologs in mice: Lethal phenotypes of Brca1, Brca2, Brca1/Brca2, Brca1/p53, and Brca2/p53 nullizygous embryos. Genes Dev 11:1226-1241.

Mitelman F, editor (1995). An International System for Human Cytogenetic Nomenclature. Basel: S Karger.

Orban TI and Olah E (2001). Expression profiles of BRCA1 splice variants in asynchronous and in G1/S synchronized tumor cell lines. Biochem Biophys Res Commun 280:32-38. 
Rennstam K, Baldetorp B, Kytola S, Tanner M, and Isola J (2001). Chromosomal rearrangements and oncogene amplification precede aneuploidization in the genetic evolution of breast cancer. Cancer Res 61:1214-1219.

Saal LH, Troein C, Vallon-Christersson J, Gruvberger S, Borg $\AA$, and Peterson C (2002). BioArray Software Environment (BASE): A platform for comprehensive management and analysis of microarray data. Genome Biol 3(8): SOFTWARE0003.

Staff S, Nupponen NN, Borg A, Isola JJ, and Tanner MM (2000). Multiple copies of mutant BRCA1 and BRCA2 alleles in breast tumors from germ-line mutation carriers. Genes Chromosomes Cancer 28:432-442.

Tirkkonen M, Johannsson O, Agnarsson BA, Olsson H, Ingvarsson S, Karhu R, Tanner M, Isola J, Barkardottir RB, Borg A, and Kallioniemi OP (1997). Distinct somatic genetic changes associated with tumor progression in carriers of BRCA1 and BRCA2 germ-line mutations. Cancer Res 57: 1222-1227.

Tomlinson GE, Chen TT, Stastny VA, Virmani AK, Spillman MA, Tonk V, Blum JL, Schneider NR, Wistuba II, and Shay JW (1998). Characterization of a breast cancer cell line derived from a germ-line BRCA1 mutation carrier. Cancer Res 58:3237-3242.
Venkitaraman AR (2002). Cancer susceptibility and the functions of BRCA1 and BRCA2. Cell 108:171-182.

Welcsh PL, Owens KN, and King MC (2000). Insights into the functions of BRCA1 and BRCA2. Trends Genet 16:69-74.

Wilson CA, Payton MN, Elliott GS, Buaas FW, Cajulis EE, Grosshans D, Ramos L, Reese DM, Slamon DJ, and Calzone FJ (1997). Differential subcellular localization, expression and biological toxicity of BRCA1 and the splice variant BRCA1delta11b. Oncogene 14:1-16.

Xu X, Wagner K-U, Larson D, Weaver Z, Li C, Ried T, Hennighausen L, Wynshaw-Boris A, and Deng C-X (1999). Conditional mutation of Brca1 in mammary epithelial cells results in blunted ductal morphogenesis and tumour formation. Nat Genet 21:37-43.

Yang YH, Dudoit S, Luu P, Lin DM, Peng V, Ngai J, and Speed TP (2002). Normalization for cDNA microarray data: A robust composite method addressing single and multiple slide systematic variation. Nucleic Acids Res 30:e15.

Zheng L, Li S, Boyer TG, and Lee WH (2000). Lessons learned from BRCA1 and BRCA2. Oncogene 19:6159-6175. 